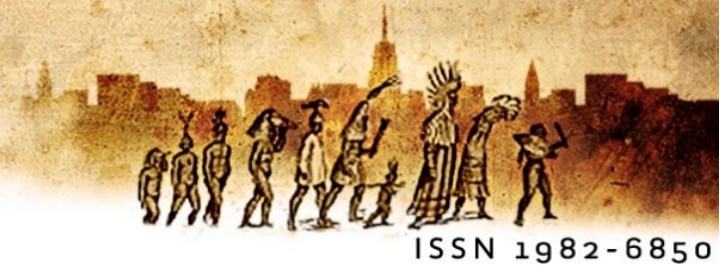

\title{
O fenômeno da interdição de vocabulário na perspectiva da teoria da linguagem de Eugenio Coseriu: uma análise de textos midiáticos
}

\section{The phenomenon of vocabulary interdiction from the perspective of Eugenio Coseriu's language theory: an analysis of media texts}

Wesley Pinto Hoffmanni (PPGL/UPF)

Sumaya Ferreira Guedes ${ }^{\mathrm{ii}}$ (UNEMAT)

Resumo: A criação metafórica é observada como um elemento constitutivo da linguagem que apresenta diferentes enfoques teóricos. Neste trabalho, a partir da Teoria da Linguagem de Eugenio Coseriu, na qual ele indica o fenômeno da interdição de vocabulário, revemos os traços que compõem esse fenômeno. Dessa forma, o presente estudo tem por objetivo analisar a ocorrência do fenômeno da interdição de vocabulário em uma materialidade textual. A partir dos pressupostos teóricos de Coseriu (1982, 2007), realizamos uma pesquisa de natureza aplicada, exploratória, bibliográfica e documental na análise de um material constituído por uma capa de revista publicada pela Contigo! no ano de 2021. Concluímos que a fantasia humana difunde diversos significados metafóricos em busca de novas imagens expressivas que nomeiam e distinguem o que a intuição conhece, em uma contínua renovação de metáforas.

Palavras-chave: Fenômeno da interdição de vocabulário; Criação metafórica; Teoria da Linguagem; Teoria Coseriana.

\begin{abstract}
The metaphorical creation is seen as a constitutive element of language that presents different theoretical approaches. In this work, based on Eugenio Coseriu's Theory of Language, in which he indicates the phenomenon of vocabulary interdiction, we review the features that make up this phenomenon. Thus, the present study aims to analyze the occurrence of the phenomenon of interdiction of vocabulary in a textual materiality. Based on Coseriu's $(1982,2007)$ theoretical assumptions, we carried out an applied, exploratory, bibliographic and documentary research in the analysis of a text consisting of a magazine cover published by Contigo!
\end{abstract}


in the year 2021. We conclude that human fantasy spreads several metaphorical meanings in search of new expressive images that name and distinguish what intuition knows, in a continuous renewal of metaphors.

Keywords: Vocabulary interdiction phenomenon; Metaphorical creation; Language Theory; Coserian Theory.

\section{Introdução}

Os estudos referentes à criação metafórica recebem diferentes enfoques teóricos, de forma que, na concepção da Teoria da Linguagem de Eugenio Coseriu (1982), a metáfora é verificada como um elemento constitutivo da linguagem. Nessa perspectiva, a partir do cognoscível, o ser humano apreende a realidade através da intuição, por meio da qual ele cria um mundo específico e dá lugar a linguagem como ponte mediadora entre a consciência dos indivíduos e o mundo, em infinitas criações metafóricas.

Nesse sentido, a partir da Teoria da Linguagem de Eugenio Coseriu, este estudo tem por objetivo analisar a ocorrência do fenômeno da interdição de vocabulário em uma materialidade textual. A partir dos pressupostos teóricos de Coseriu (1982, 2007), realizamos uma pesquisa de natureza aplicada, exploratória, bibliográfica e documental na análise de um material constituído por uma capa de revista publicada pela Contigo! no ano de 2021.

Para além desta introdução, organizamos o texto em três seções: na primeira delas, intitulada "Definições sobre a linguagem", discutimos os elementos constitutivos da linguagem; na segunda, "Criação metafórica na linguagem e o fenômeno da interdição de vocabulário", discorremos sobre a criação metafórica, em especial sobre o fenômeno da interdição de vocabulário; na terceira seção, "O fenômeno da interdição de vocabulário em uma análise midiática", realizamos uma breve análise de um material constituído por uma capa de revista, a partir dos pressupostos teóricos de Coseriu $(1982,2007)$ acerca da criação metafórica; por fim, tecemos algumas considerações desenvolvidas com o estudo.

\section{Definições sobre a linguagem}

De acordo com Pinheiro (2018), Eugenio Coseriu nasceu no ano de 1921, na Romênia. Foi professor de Linguística Geral e indo-europeia na Universidade de Montevidéu, no 
Uruguai. Em 1963, foi professor das Disciplinas de Linguística Românica e Geral, em Tübingen, na Alemanha.

Ainda, conforme o pesquisador, Coseriu desenvolveu princípios fundamentais de sua Teoria da Linguagem baseando-se na linguística estrutural, tendo explorado a maioria das áreas da linguística geral e uma quantidade expressiva de estudos de línguas específicas (PINHEIRO, 2018, p. 02).

Podemos conceber a linguagem sob diferentes enfoques quanto ao seu objeto, de forma que podemos nos perguntar quais as condições para a produção da linguagem, ou seja, como a linguagem ocorre? Coseriu (1982) aclara que a língua é um fenômeno social produzido em sociedade e determinado, em boa parte, socialmente. São necessários pelo menos um falante e um ouvinte para que os signos possam ser compreendidos e aceitos pelos falantes de uma comunidade, na qual os signos dependem "[...] em parte, da composição, do estado e da história da própria comunidade" (COSERIU, 1982, p. 54).

Nessa perspectiva, a linguagem é uma instituição social sistemática. Conforme Coseriu (1982), há uma continuidade diacrônica do sistema da língua que se manifesta como os atos linguísticos comuns com certa semelhança, em uma comunidade. Destarte, Coseriu assevera que "[...] mais do que duas realidades diferentes, 'língua' e 'fala' são apenas duas visões diferentes, duas maneiras diferentes de encarar a mesma realidade: 'língua' e 'fala' não são momentos sucessivos, mas simultâneos e inseparáveis duma única realidade, que chamamos linguagem" (COSERIU, 1982, p. 54-55). Essa observação do autor revela que língua e fala são constituintes da linguagem que são interdependentes e não se fundam na oposição.

De acordo com Coseriu (1982), a linguagem é uma modalidade particularizada do homem em contato com sua realidade, na tradução, esclarecimento, designação e expressão do mundo mediante os símbolos. Em conformidade com Coseriu (1982, p. 57), "os símbolos são [...] formas cujo conteúdo é um conhecimento. [...] A linguagem é essencialmente atividade cognoscitiva: uma atividade cognoscitiva que se realiza mediante símbolos".

Em conformidade com Coseriu (1982), ao tomarmos a linguagem enquanto atividade, desvelamos elementos essenciais: na concepção dessa Teoria da Linguagem, os símbolos são recriados a cada ato de fala, ao passo que todo ato linguístico tem como pressuposto operações cognoscitivas, ou seja, são presentes complexas relações cognoscitivas. Um 
objeto se enquadra em um conceito, de forma que o movimento cognoscitivo vai do objeto ao conceito, para o falante, e do conceito ao objeto, para o ouvinte.

A seguir, na Figura 1, apresentamos uma ilustração das operações cognoscitivas nos atos de fala, propostas por Coseriu (1982).

Figura 1 - operações entre falante e ouvinte

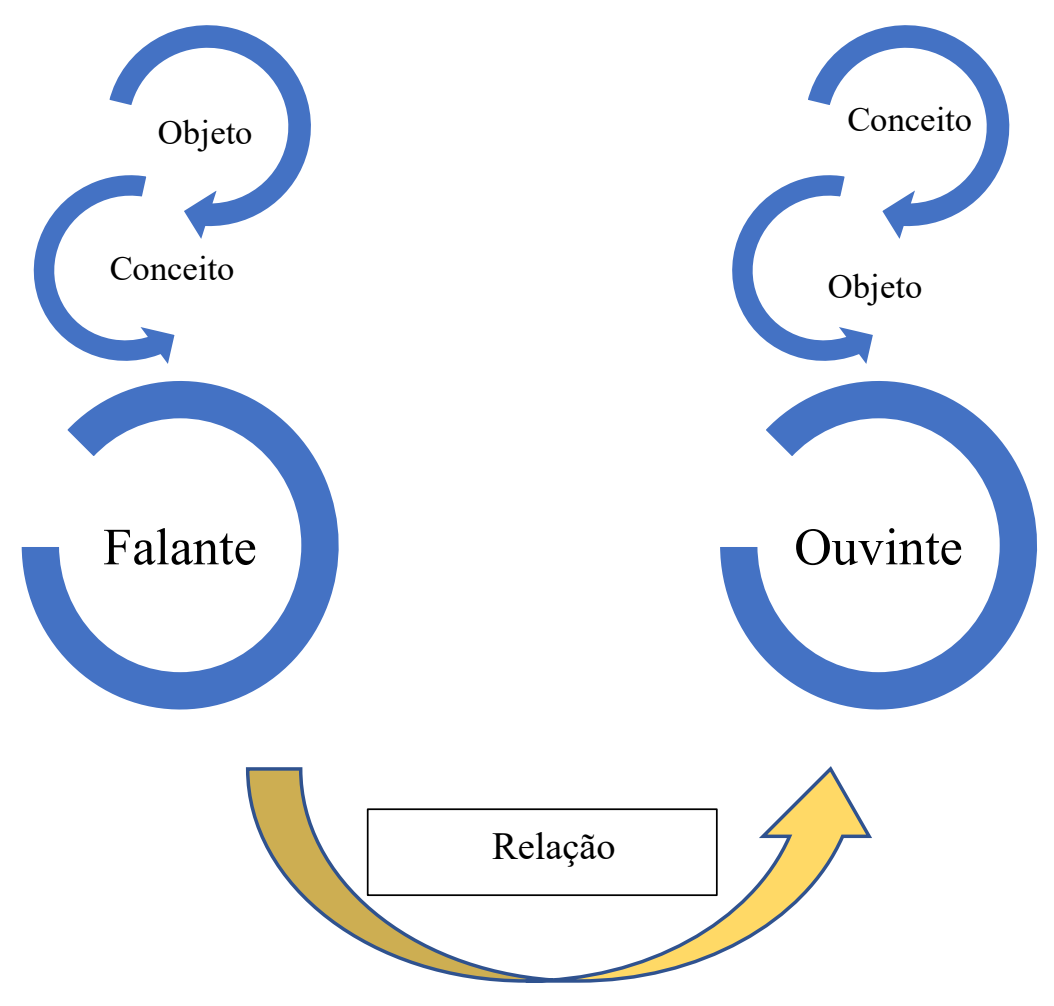

Fonte: elaborado pelos pesquisadores com base em Coseriu (1982).

Recorremos ao exemplo de Coseriu (1982), responsável por elucidar que a frase "o cachorro brinca", por exemplo, significa que este objeto está na classe cachorro e que a atividade, em particular, é um exemplo da classe brincar. Dessa forma, é estabelecida uma relação de simultaneidade e interdependência no falante e no ouvinte.

Como pode-se observar na Figura 1, o movimento é de interdependência dos elementos que apresentam as posições intercambiadas entre a posição do sujeito que fala e o sujeito que ouve na relação dos quatro elementos envolvidos nesse circuito: objeto, conceito, falante e ouvinte. 
A língua, reconhecida comumente como o objeto da linguagem, é uma atividade repetível, ainda que não possa ser perfeitamente repetida; é um esquema das atividades de linguagem realizadas. Dessa forma, a língua, nessa perspectiva, não pode ser tomada como o único e completo produto da linguagem (COSERIU, 1982).

O autor reconhece que a língua não é suficiente para a expressão de todos os atos particulares de fala, já que o conteúdo cognoscitivo não é idêntico em todas as situações. Há uma criação constante na linguagem que perpassa todos os atos de falar. Coseriu (1982) também enfoca na linguagem como um conhecimento criador com fatores que constituem e que distinguem o homem, mais nitidamente os homens de outros seres da natureza. Conforme o autor, não é a linguagem, propriamente dita, que distingue os sujeitos de outros seres, mas sim o que se chama conjuntamente de cultura. Em conformidade com Coseriu,

De fato, como conhecimento criador, a linguagem tem todas as características das atividades criadoras do espírito cujos resultados não são materiais ou em que o material é o que menos importa - por ser simples veículo ou suporte de essenciais elementos formais - e que se chamam conjuntamente cultura: é uma forma de cultura, talvez a mais universal de todas, e, de qualquer modo, a primeira que distingue imediata e nitidamente o homem dos outros seres da natureza (COSERIU, 1982, p. 60).

A partir da linguagem tomada como uma das formas mais universais da cultura, que carrega consigo a expressão de um indivíduo social, reconhecemos que são inúmeras as tentativas de classificar a realidade mediante analogias estabelecidas pelos sujeitos. Dessa forma, a seguir, na seção "Criação metafórica na linguagem e o fenômeno da interdição de vocabulário", discorreremos sobre essas analogias estabelecidas na concepção das metáforas, na perspectiva da Teoria da Linguagem Coseriana.

\section{Criação metafórica na linguagem e o fenômeno da interdição de vocabulário}

Partindo-se dos fatores que constituem a linguagem, Coseriu defende que o conhecimento linguístico, muitas das vezes, é também um conhecimento metafórico, mediante imagens, o que fez Coseriu se questionar acerca de uma unidade universal da fantasia humana, que se apresenta com muito mais intensidade do que as diferenças étnicas ou culturais, por exemplo (COSERIU, 1982). 
Procuramos classificar a realidade por meio de analogias estabelecidas em face de imagens, poeticamente, entre visões da fantasia criadora dos sujeitos. Segundo Coseriu,

Encontramo-nos em face do que, num sentido muito amplo, chamamos metáfora, que não entendemos aqui como simples transposição verbal, como "comparação abreviada", mas como expressão unitária, espontânea e imediata (isto é, sem nenhum "como" intermediário) duma visão, duma intuição poética, que pode implicar uma identificação momentânea entre objetos distintos (cabeça-mate, ou uma hiperbolização dum aspecto particular do objeto) (COSERIU, 1982, p. 63).

Coseriu (1982) pontua que nem todas as metáforas produzidas via atos linguísticos ficam presentes na língua, na tradição de uma comunidade. Quando as metáforas entram na língua, paulatinamente, vão se tornando convencionais e perdem o valor imagético. De acordo com Coseriu (1982, p. 63), "Existe, pois, um aspecto metafórico-convencional dos signos, ou, pelo menos, de certos signos que, dentro de uma tradição, continuam a ser intuídos como imagem porque não tem relação expressiva com outros signos do sistema da comunidade".

No contexto brasileiro podemos pensar no elemento "perna da mesa" - essa expressão comumente utilizada para referenciar a estrutura que suporta uma mesa é constituída pela palavra "perna", que se refere à estrutura corporal de seres humanos. No entanto, ao longo do tempo, essa imagem foi se tornando convencional na comunidade linguística brasileira e perdeu o valor imagético. Em contrapartida, a dissociação com outros signos do sistema da comunidade faz com que os sujeitos percebam que a expressão é conjunto de uma criação metafórica adotada por uma comunidade.

Por conta da vinculação histórica e cultural da linguagem, certos signos podem perdem o processo de metáfora, assim como outros podem passar a estabelecer novas metáforas. Consoante Coseriu,

$\mathrm{E}$, assim como certos signos se "desmetaforizam" com o tempo, tornandose "próprios" e "convencionais", outros signos, próprios em suas origens, podem chegar a se "metaforizar", podem tornar-se figurados pela evolução das coisas designadas, embora se trate de um caso mais raro e embora a metaforização passe amiúde despercebida (COSERIU, 1982, p. 63-64).

Com relação à expressividade, Coseriu (1982) observa que as crianças, no processo de aprendizagem da língua materna, reconhecem relações surpreendentes estabelecidas entre os signos, que os adultos não percebem. No caso do aprendizado de um idioma estrangeiro, 
essas crianças criam jogos de palavras que não são desenvolvidos por crianças que têm aquela língua como materna. De acordo com Coseriu (1982), as dúvidas concernentes à significação aumentam as possibilidades de associações no sistema da língua.

Cabe salientar que o valor metafórico de um signo nem sempre é resultado da realidade histórica, de forma que a história da metáfora não coincide com a sua etimologia, o que Coseriu (1982) alerta como um indício da dissociação entre sincronia e diacronia, apontada por Saussure.

À vista disso, Coseriu (1982) levanta algumas inquietações, tais como: Quais são as razões da criação metafórica na linguagem? Podem ser investigadas as relações profundas da criação linguística? O linguista pontua que não é possível responder objetivamente a essas questões, já que a invenção é inerente à linguagem em sua definição. O linguista destaca:

O que se pode indicar são as razões da maior ou menor aceitabilidade duma invenção numa determinada comunidade. São, estas, em primeiro lugar, razões de prestígio do criador e de expressividade do signo inventado; ou razões culturais mais gerais, como a substituição duma cultura por outra, ou o contínuo progresso cultural, a contínua irrupção no horizonte das consciências linguísticas de objetos e ideias novas, que exigem conhecimento e classificação (COSERIU, 1982, p. 68).

De acordo com Coseriu (1982), o tabu linguístico é um fenômeno no qual certas palavras que se relacionam a superstições e mitos são evitadas e, então, substituídas através de empréstimos, como eufemismos, metáforas, antífrases. Em conformidade com Coseriu (1982, p. 69), "o tabu linguístico deve-se, essencialmente, a crença (muito arraigada nas sociedades primitivas, mas documentável também em sociedades mais adiantadas) em certa "magia das palavras", a certa identificação entre o nome e a coisa nomeada."

Nessa perspectiva o nome correspondente pode ser considerado perigoso, no sentido de que, ao nomear o objeto, os sujeitos poderiam estar evocando esse objeto/entidade. Assim, as comunidades preferem empregar palavras ou expressões que se distanciem da palavra própria, nomeando o objeto de formas diferentes. Podemos observar essa ocorrência em comunidades religiosas que evitam designar os nomes próprios de certos demônios ou entidades, ou até mesmo filmes de terror que fazem uso do recurso linguístico para trazer à cena certos seres fantásticos.

Neste momento chegamos a um dos conceitos seminais de Coseriu (1982) acerca da criação metafórica. Segundo o autor, o exemplo do tabu linguístico é apenas um aspecto de 
um fenômeno amplo, denominado por interdição de vocabulário, que não somente se ocupa de superstições e crendices, mas também de várias outras motivações de origem emocional ou social, como a polidez, a cortesia, boas maneiras, decência humana, a gentileza, entre outras motivações (COSERIU, 1982).

Coseriu (1982) aclara que as comunidades evitam expressões e palavras consideradas cruas ou ofensivas. Dessa forma, ao se dirigir a um parente, evitam-se palavras e expressões que demonstrem violência ou ofensa perante esses sujeitos com alguma ligação familiar mais próxima.

O fenômeno da interdição de vocabulário também se manifesta, por exemplo, quando os sujeitos evitam nomear partes do corpo humano por considerarem as áreas corpóreas indecentes, em especial os órgãos genitais, que são metaforizados com palavras que remetem a termos científicos, ou a termos mais populares, como o empréstimo de imagens que remetem a frutas, legumes, animais, entre outros. Já no ato sexual, empregamse eufemismos, como o exemplo de "deitar-se com alguém", "dormir com alguém" (COSERIU, 1982).

A partir do que foi apresentado, na próxima seção, intitulada "O fenômeno da interdição de vocabulário em uma análise midiática", desenvolvemos uma análise de um material com base nos pressupostos da criação metafórica na linguagem, propostos por Coseriu (1982).

\section{O fenômeno da interdição de vocabulário em uma análise midiática}

Nas seções anteriores, foi possível observar a ocorrência da criação metafórica na linguagem como uma mediadora entre a consciência e o mundo. Dessa forma, nesta seção, a partir dos pressupostos teóricos de Coseriu $(1982,2007)$, realizamos a análise de um material constituído por uma capa de revista publicada pela Contigo! no ano de 2021.

Partimos da contextualização da materialidade textual, de modo a alcançar o objetivo do estudo por meio de uma análise da ocorrência do fenômeno da interdição de vocabulário em um texto midiático. As reflexões de análise estão distribuídas da seguinte forma:

a) Contextualização do material e sua inserção social, bem como sua constituição, local de criação e motivações para o seu desenvolvimento;

Eutomia, Recife, 30(1): 79-92, Dez. 2021 
b) pressupostos teóricos de Coseriu $(1982,2007)$ acerca da criação metafórica, em especial, o fenômeno da interdição de vocabulário;

c) verificação da ocorrência do fenômeno da interdição de vocabulário no material selecionado. Na Figura 2, ilustramos o percurso metodológico adotado na análise do material:

Figura 2 - percurso metodológico

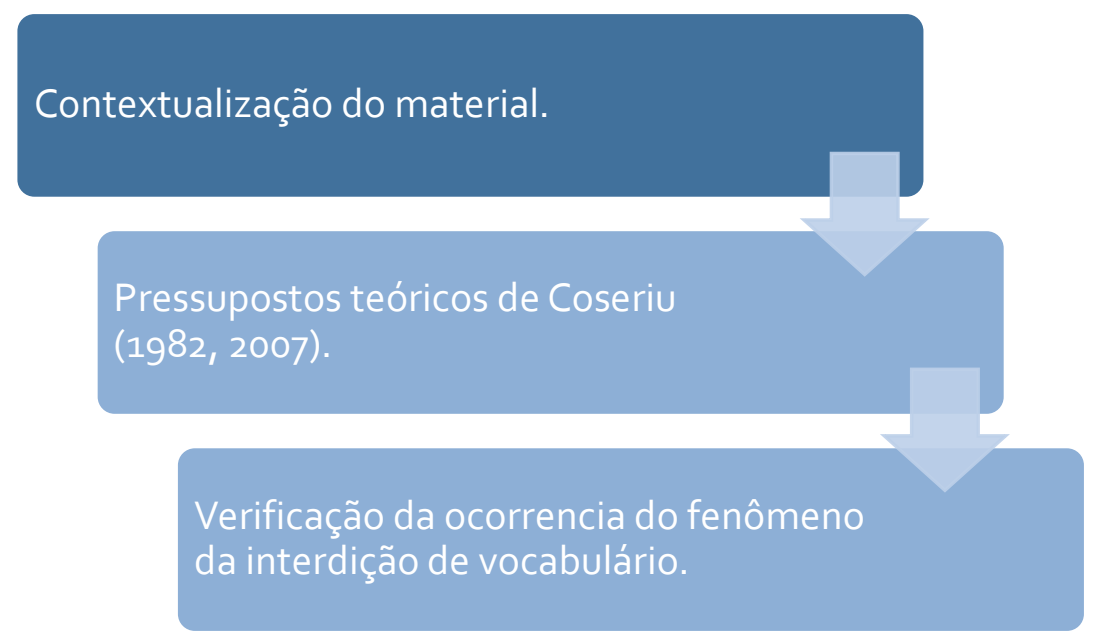

Fonte: elaborada pelos pesquisadores (2021).

Conforme ilustra a Figura 2, iniciamos a contextualização do material de análise: o material selecionado é constituído por uma capa da Revista Contigo!, publicada durante o ano de 2021. A revista em questão é uma materialidade de alcance nacional do Brasil que se ocupa de diversos assuntos, sobretudo de temáticas ligadas ao entretenimento, novidades e notícias referentes ao mundo dos famosos.

A capa selecionada é composta por uma edição especial referente ao renomado ator brasileiro Paulo Gustavo. Paulo Gustavo foi uma das vítimas da COVID-19, doença que afetou expressivamente o contexto brasileiro. O ator carioca faleceu no dia 04 de maio de 2021, por conta de complicações advindas da doença, deixando um grande legado para o humor brasileiro. Sua morte foi recebida pelos fãs e pelos brasileiros, em geral, com muito pesar, já que o reconhecido ator era um representante do humor cotidiano brasileiro nas obras cinematográficas e televisivas das quais participou.

Um de seus maiores trabalhos no cinema foi a franquia de filmes intitulada Minha Mãe é uma Peça, na qual Paulo Gustavo interpretava a personagem Dona Hermínia, uma mãe 
brasileira, divorciada, com dois filhos, que acompanha a transição da juventude até a vida adulta de seus filhos, sempre com muito bom humor, elemento que foi advindo da inspiração pessoal do ator em sua mãe, conhecida como Dona Déa.

A capa selecionada apresenta uma edição temática em homenagem ao legado do ator. A seguir, na Figura 3, apresentamos a capa da Revista Contigo!

Figura 3- Capa da Revista Contigo!

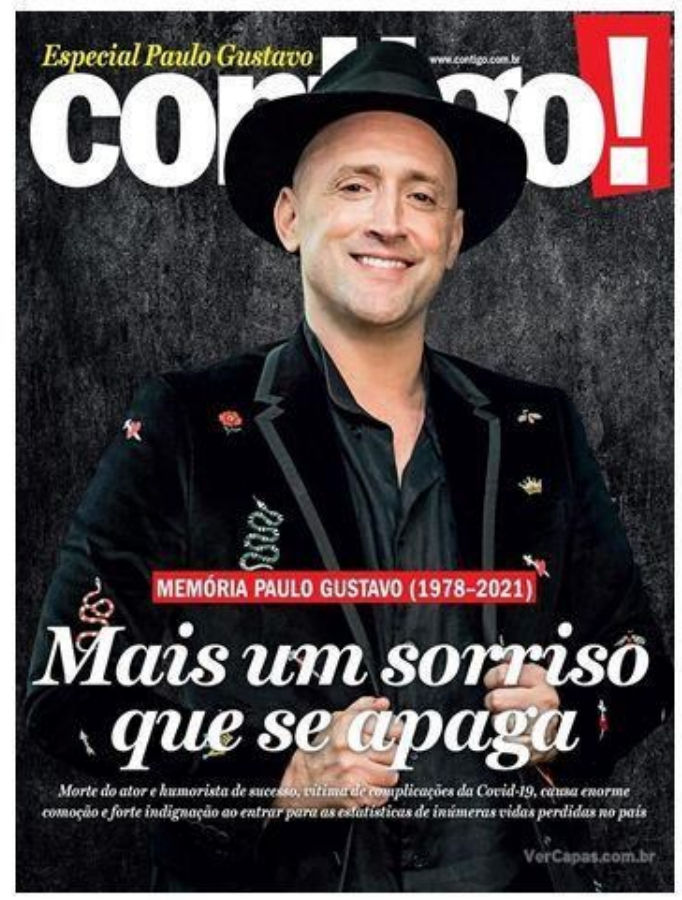

Fonte: (MAGAZINELUIZA, 2021²)

Com base nas contribuições de Coseriu $(1982,2007)$, nesta análise, focamos nos elementos verbais da capa. Podemos observar, no meio da capa, em fundo vermelho, a expressão verbal "Memória Paulo Gustavo (1978-2021); mais abaixo, a expressão maior em fonte da cor branca "Mais um sorriso que se apaga".

Em conformidade com Coseriu (1982), a linguagem é dependente das normas complexas estabelecidas pelos sujeitos falantes. Segundo Coseriu (1982, p. 67), "a linguagem não tem existência autônoma e é governada, segundo normas infinitamente complexas,

1 Disponivel em: https://www.magazineluiza.com.br/revista-contigo-especial-paulogustavo/p/agbijggb5e/li/otli/. Acesso em 03 out. 2021

Eutomia, Recife, 30(1): 79-92, Dez. 2021 
pelos indivíduos falantes: por todos os falantes duma comunidade e por cada um deles, em cada ato linguístico concreto". Dessa forma, observamos no ato linguístico concreto da capa da revista a escolha de expressões intencionalmente dispostas a representar determinadas imagens metafóricas que combinam com o que é estabelecido e normatizado pela comunidade de falantes.

São relações referentes ao ato linguístico desempenhado pela revista que são particulares ao seu público leitor, com associações subjetivas e metafóricas estabelecidas por meio das recorrentes intuições que formam imagens metafóricas nas comunidades de falantes. Para que o ato linguístico seja aceito por uma comunidade, recorremos ao conceito apresentado como tabu linguístico, que é "o fenômeno pelo qual certas palavras relacionadas com superstições e crenças são evitadas e substituídas por empréstimos, eufemismos, circunlóquios, metáforas, antífrases, etc (COSERIU, 1982, p. 69).

Reconhecemos que há um tabu linguístico com relação à morte no contexto comunicativo de circulação da revista. Dessa forma, por conta do tabu linguístico, a revista escolhe, dentre as possibilidades da língua, apagar o termo "morte" das manchetes principais.

Além do aspecto referente ao tabu linguístico, constatamos, principalmente, o fenômeno da interdição de vocabulário, no qual, de acordo com Coseriu (1982, p. 71), "evitam-se expressões e palavras que se consideram demasiadamente cruas ou descorteses, ou indecentes. [...] parece-nos demasiadamente cru, mormente se [...] falamos na presença de parentes do defunto, dizer que alguém morreu".

Consoante Coseriu (1982), o homem reconhece e designa metaforicamente os fenômenos da natureza e da vida humana, como o nascer e o morrer. Dessa forma, a expressão apresentada na capa selecionada "Mais um sorriso que se apaga", metaforicamente, por meio do fenômeno da interdição de vocabulário, reconstrói a informação referente à morte de um homem importante para o Brasil, sobretudo, por ser um ator dedicado ao humor. Há um jogo na seleção das palavras em questão que relaciona a expressão da morte de Paulo Gustavo à sua profissão, o que gera uma interessante combinação metafórica recorrida pela revista.

Segundo Pinheiro e Moreira (2018, p. 17), "o caminho que conduz à hermenêutica do sentido passa, necessariamente, pela identificação dos procedimentos que cada texto, de 
forma única e particular, possui". Esse caminho é reconhecido no nível individual da linguagem (COSERIU, 2007).

Conforme Coseriu (1982), há uma gradação do sistema metafórico, que vai desde a extrema necessidade de substituição de uma criação, até a zombaria. Neste caso da capa, verificamos que a revista em questão trabalha com relativa liberdade para a seleção de palavras que criem um ato linguístico capaz de aproximar os leitores de um assunto delicado na revista e os consumidores de revistas, em geral, que procuram se informar sobre uma temática que esteve arraigada na sociedade brasileira.

Consoante Coseriu (1982, p. 75), "A alegria, a tristeza, a dor e o medo do homem, a sua maneira de considerar o mundo e a sua atitude para com ele, tudo isso se reflete na palavra, no ato de criação linguística". Destarte, nossos sentimentos e emoções provocadas por esses sentimentos são expressos nos atos da criação linguística. Neste caso da revista, pudemos observar que a comoção coletiva e o carinho mobilizado nas homenagens ao ator estão presentes nas escolhas que compõem o ato linguístico na capa da revista.

A revista recorre ao fenômeno da interdição de vocabulário para se expressar de forma sensível, respeitosa, a partir das associações estabelecidas em um ato linguístico singular. Conforme Coseriu (1982, p. 76), "as palavras tornam-se nobres ou vulgares de acordo com quem as empregue, de acordo com as associações fônicas e significativas que despertem, de acordo com as situações em que sejam utilizadas".

Partindo-se das importantes reflexões de Eugenio Coseriu $(1982,2007)$ acerca da linguagem e da criação metafórica, na próxima seção, apresentamos nossas considerações finais.

\section{Considerações finais}

Nesse movimento, este estudo teve por objetivo analisar a ocorrência do fenômeno da interdição de vocabulário em uma materialidade textual. A partir dos pressupostos teóricos de Coseriu (1982, 2007), realizamos uma pesquisa de natureza aplicada, exploratória, bibliográfica e documental na análise de um material constituído por uma capa de revista publicada pela Contigo! no ano de 2021.

Consideramos o objetivo alcançado, uma vez que pudemos observar a ocorrência do fenômeno da interdição do vocabulário em um ato linguístico real, na materialidade que nos 
serviu de material de análise. A verificação da criação metafórica abre espaço para uma verificação linguística que leva em conta elementos que compõem os textos que comumente circulam em diferentes esferas sociais. Assim, percebemos que a criação metafórica está presente em todas as atividades humanas e se desenvolve através de atos linguísticos singulares.

Com relação às limitações deste estudo pontuamos a seleção do material e conceitos relacionados, já que materialidades verbais mais complexas, bem como outros conceitos referentes à teoria da linguagem de Eugenio Coseriu, que podem ser explorados por outros pesquisadores. Ensejamos que este breve estudo possa motivar outros pesquisadores a investigarem diferentes perspectivas concernentes à Teoria da Linguagem de Eugenio Coseriu, ainda timidamente estudada no contexto brasileiro e carente de expansão em diferentes campos de atuação.

Por fim, concluímos que o lugar da criação metafórica na linguagem é amplo, de forma que a linguagem é sempre perpassada pela atividade poética e criadora. A fantasia que nos torna humanos instiga os sujeitos a desenvolverem novas criações em novos atos linguísticos.

\section{Referências}

COSERIU, Eugenio. O homem e sua linguagem. Rio de Janeiro: Presença, Coleção linguagem, 1982.

COSERIU, Eugenio. Lingüística del texto: Introducción a la hermenêutica del sentido. Edición de Óscar Loureda Lamas. Madri: Arco Libros, 2007.

MAGAZINELUIZA. Revista: Contigo! Especial Paulo Gustavo. Disponível em https://www.magazineluiza.com.br/revista-contigo-especial-paulo-

gustavo/p/agb1jggb5e/li/otli/. Acesso em o3 out. 2021.

PINHEIRO, Clemilton Lopes. Eugenio Coseriu e a linguística do texto no Brasil. ORGANON, v. 33, p. 01-16, 2018.

PINHEIRO, Clemilton Lopes; MOREIRA, Juzelly Fernandes Barreto. Uma Proposta de Concepção de Estilo Fundada na Linguística Textual de Eugênio Coseriu. Revista da Anpoll, v.1, n.45, p. 248-262, 2018. 
' Mestrando em Letras pelo Programa de Pós-Graduação da Universidade de Passo Fundo, na linha de pesquisa Leitura e Formação do Leitor. Licenciado em Letras Português, Inglês e Respectivas Literaturas pela Universidade de Passo Fundo.

ORCID: https://orcid.org/0000-0002-5814-1573.

E-mail: wesleywph@gmail.com.

ii Professora e pesquisadora no Programa de Pós-Graduação em Educação da Universidade do Estado de Mato Grosso (UNEMAT).

ORCID: https://orcid.org/0000-0002-1613-3647.

E-mail: sumaya.guedes@unemat.br.

Recebido em $13 / 10 / 21$

Aprovado em 26/12/21

(ब) (1)

Todo conteúdo da Revista Eutomia está sob a Licença Creative Commons Atribuição 4.0 Internacional.

Eutomia, Recife, 30(1): 79-92, Dez. 2021 